\title{
STRATEGI PEMASARAN DALAM MEMPENGARUHI KEPUTUSAN PEMBELIAN MELALUI NIAT SEBAGAI MEDIASI
}

\author{
Angga Febrian ${ }^{1}$ \\ Cinthia Annisa Vina Hapsari ${ }^{2}$
}

${ }^{1}$ Universitas Teknokrat Indonesia, Lampung, Indonesia
angga_febrian@teknokrat.ac.id, 082377922212
${ }^{2}$ Universitas Teknokrat Indonesia, Lampung, Indonesia
cinthiavinahapsari@gmail.com, 081285180407

\begin{abstract}
Marketing Strategies in Influencing Purchasing Decisions Through Intention as Mediation. Changes in an increasingly dynamic era makes companies have to increase who want to improve marketing. Using marketing mix variables and service quality that can increase consumer intention in buying a car. This study aims to look at marketing strategies that can be used in influencing consumer purchasing decisions. The sample used is consumers who have bought a car from 2015 to 2018 in Lampung. Using the help of SmartPls software analysis tools in Processing data. The results of the study describe the marketing mix and the quality of simultaneous service that influences purchase intentions and purchasing decisions. The two independent variables must be carried out simultaneously, if only the marketing mix is used then the results are not significant. Training to improve employee knowledge of products sold and good attitude to consumers is an important key in the success of the company's sales.
\end{abstract}

Keywords: Marketing Mix; Service Quality; Intention and Purchasing Decision.

\section{Abstrak: Strategi Pemasaran Dalam Mempengaruhi Keputusan Pembelian Melalui Niat}

Sebagai Mediasi. Perubahan zaman yang semakin dinamis membuat perusahaan harus mampu dengan cepat mengikuti perkembangan yang berdampak pada cara melakukan strategi pemasaran yang tepat dalam meningkatkan penjualan. Menggunakan variabel bauran pemasaran dan kualitas pelayanan yang dapat mempengaruhi niat konsumen dalam membeli mobil. Penelitian ini bertujuan untuk melihat strategi pemasaran yang dapat digunakan dalam mempengaruhi keputusan pembelian konsumen. Sampel yang digunakan adalah konsumen yang sudah membeli mobil dari tahun 2015 sampai 2018 di Lampung. Menggunakan bantuan alat analisis software SmartPls dalam pengolahan data. Hasil penelitian menjelaskan bahwa bauran pemasaran dan kualitas pelayanan secara simultan mempengaruhi niat pembelian serta keputusan pembelian. Kedua variabel independen tersebut harus secara simultan dilakukan, jika hanya bauran pemasaran saja yang digunakan maka hasinya tidak signifikan. Pelatihan untuk meningkatkan pengetahuan karyawan terhadap produk yang dijual serta sikap yang baik kepada konsumen menjadi kunci penting dalam keberhasilan penjualan perusahaan.

Kata Kunci: Bauran Pemasaran; Kualitas Pelayanan; Niat dan Keputusan Pembelian 


\section{PENDAHULUAN}

Dalam kehidupan sehari-hari masyarakat saat ini tidak terlepas dari penggunaan transportasi untuk menunjang kegiatan. Transportasi yang sering digunakan untuk masyarakat menengah keatas yaitu mobil, baik digunakan untuk mendukung kegiatan perekonomian maupun hanya untuk sekedar pemenuhan keinginan. Melihat pangsa pasar kendaraan mobil di Indonesia yang mempunyai peluang cukup besar bagi pelaku otomotif, membuat perusahaan otomotif dunia berlombalomba dalam melakukan ekspansi pasar di Indonesia salah satunya di Provinsi Lampung.

Pada tabel 1 dapat dilihat penjualan mobil belum maksimal dalam peningkatan dari tahun sebelumnya. Perusahaan harus dapat melakukan inovasi dan kreatif dalam menerapkan strategi pemasaran agar mendapatkan umpan balik konsumen.

Beberapa perusahaan multinasional otomotif mobil berlomba-lomba dalam memenangkan persaingan. Tentunya suatu perusahaan dalam melakukan perdagangan yang semakin bersaing, maka dituntut harus mempunyai strategi yang efektif dan efisien agar tetap mendapatkan keuntungan maksimal dan tidak tersingkir oleh pesaingnya. Strategi menjadi peran yang sangat penting dalam melakukan pencapaian keberhasilan perusahaan tersebut.

Salah satu upaya yang dilakukan oleh perusahaan dalam melakukan pemasaran adalah dengan strategi pemasaran.
Pemasar mempunyai tanggung jawab terhadap produksi yang berkelanjutan dan kosnsumsi barang dan jasa untuk menghadapi konsumen yang semakin dinamis. Pemasar dapat menggunakan strategi untuk mendukung keberlanjutan bisnis dalam keberlangsungan hidup perusahaan (D’Souza et al., 2019)

Bauran pemasaran merupakan tindakan dan keputusan tertentu yang ditujukan pada tujuan perusahaan dan dalam memenuhi kebutuhan pelanggan. Di zaman modern ini, perusahaan beroperasi secara konstan. Keberhasilan dalam menyiapkan dan tetap menguntungkan, perlu disediakannya layanan yang dapat memenuhi kebutuhan pelanggan (Išoraitè, 2016). Manajer pemasaran harus memenuhi permintaan dari pasar yang berbeda dan juga mencocokkan persaingan di pasar dengan memberikan kepuasankepada pelanggan. Ini hanya dimungkinkan dengan perpaduan yang akurat dari semua elemen bauran pemasaran yang membantu dalam mencapai tujuan organisasi memaksimalkan laba dengan volume penjualan yang tinggi dan memperoleh pangsa pasar yang lebih tinggi (Singh, 2012).

Oleh karena itulah strategi pemasaran harus dapat memberikan gambaran yang jelas dan teratur tentang apa yang dilakukan oleh perusahaan dan menggunakan setiap kesempatan atau peluang pada beberapa sasaran pasar. Srategi bauran pemasaran dianggap masih relevan dengan model bisnis barang dan

Tabel 1.

\section{Penjualan Mobil}

\begin{tabular}{ccc}
\hline Merek & $\begin{array}{c}\text { Penjualan } \\
\mathbf{2 0 1 7}\end{array}$ & $\begin{array}{c}\text { Penjualan } \\
\mathbf{2 0 1 8}\end{array}$ \\
\hline ISUZU & 20.052 & 25.286 \\
TOYOTA & 370.015 & 356.063 \\
DAIHATSU & 185.240 & 200.178 \\
MTSUBISHI & $79.669 \%$ & 146.805 \\
HONDA & 180.971 & 162.956 \\
\hline
\end{tabular}


jasa yang mampu mempengaruhi niat konsumen dalam membeli produk. Terdapat indikator produk, promosi, tempat dan harga yang dapat membantu dalam pengukuran kinerja bauran pemasaran. Produk adalah objek berwujud yang diproduksi dan ditawarkan kepada konsumen. Harga adalah jumlah yang dibayarkan konsumen untuk produk atau layanan, biasanya merupakan biaya ekonomi. Tempat yaitu lokasi di mana suatu produk atau layanan dapat dibeli dan promosi mewakili komunikasi yang digunakan di pasar(Gordon, 2012)

Tidak hanya strategi saja yang berperan penting dalam kelangsungan hidup perusahaan, tetapi perusahaan juga harus memperhatikan bagaimana pelayanan kepada konsumen ketika sebelum dan sesudah terjadinya transaksi penjualan. Peran karyawan dalam hal ini sebagai penhubung antar perusahaan dan konsumen diperlukan terutama dalam pelayanan jasa. Kualitas pelayanan yang baik akan berdampak pada niat pembelian konsumen (Hooper, Coughlan, \& Mullen, 2013) Mengadopsi dari model penelitian sebelumnya, dalam pengukuran variabel kualitas pelayanan digunakan lima indikator yaitu tangibles yaitu fasilitas fisik dan penampilan personel, keandalan yaitu kemampuan untuk melakukan layanan yang dijanjikan secara andal dan akurat, Responsiveness yaitu kesediaan untuk membantu pelanggan, jaminan yaitu Pengetahuan dan kesopanan karyawan dan empati yaitu perhatian individual yang diberikan perusahaan kepada pelanggannya (Kitapci, Akdogan, \& Dortyol, 2014)identifying the effect of satisfaction on word of mouth (WOM. Perilaku pembelian konsumen yang dipengaruhi oleh kegiatan pemasaran perusahaan dapat diukur seberapa besar pengaruhnya terhadap niat pembelian konsumen.

Teori perilaku terencana (TPB) digunakan dalam mengukur seberapa besar pengaruh terhadap niat pembelian konsumen. Mengadopsi dari penelitian sebelumnya terdapat tiga indikator dalam kerangka kerja TPB yaitu sikap terhadap perilaku, norma subyektif, dan perilaku yang dirasakan bersama-sama mengarah pada pembentukan niat perilaku yang pada gilirannya mempengaruhi perilaku (Yadav \& Pathak, 2016)as it has improved the predictive utility of the proposed model (from $27.1 \%$ to $37.7 \%$. Norma subyektif dan manfaat yang dirasakan secara signifikan mempengaruhi pembelian. Semakin tinggi niat seseorang membeli sebuah produk, maka hasilnya akan berbanding lurus dengan tingginya angka pembelian(Lim, Osman, Salahuddin, Romle, \& Abdullah, 2016)

Tujuan penelitian ini akan melihat seberapa efektifnya kegiatan pemasaran yang sudah dilakukan oleh perusahaan mobil dalam mempengaruhi konsumen dalam membeli mobil baru di Lampung. Pada akhirnya perusahaan akan mengetahui strategi apa saja yang harus ditingkatkan, dikurangi dan bahkan dihapuskan untuk kepentingan efektifitas dan efisiensi perusahaan.

\section{METODE PENELITIAN}

Desain yang digunakan adalah penelitian kuantitatif. Populasi dalam penelitian ini adalah konsumen yang telah membeli mobil pada perusahaan-perusahaan mobil di Lampung dari tahun 2015 sampai bulan September 2018. Prosedur teknik Probability Sampling yang dipakai yaitu Simple Random Sampling karena pengambilan sampel dari populasi dilakukan secara acak tanpa memperhatikan strata yang ada dalam populasi itu.

Untuk mendapatkan data dalam penelitian ini, dilakukan dengan metode wawancara dan penyebaran kuesioner dengan menggunakan skala likert. Jumlah sampel yang digunakan sebanyak 100 konsumen yang sudah membeli mobil pada tahun 2015 sampai 2018 dengan pembagian karakteristik responden dilihat pada tabel 2 .

Selanjutnya data akan diolah menggunakan alat PLS. Pengolahan data menggunakan PLS menjadi alat pengukur 
Tabel 2.

Responden

\begin{tabular}{ccc}
\hline \hline Keterangan & Klasifikasi & Jumlah \\
\hline Jenis Kelamin & Pria & 57 \\
& Wanita & 43 \\
\hline Pekerjaan & PNS & 18 \\
& Wiraswasta & 35 \\
& Karyawan Swasta & 47 \\
\hline Umur & $20-29$ th & 58 \\
& $30-39$ th & 36 \\
& $40-49$ th & 5 \\
& $>50$ & 1 \\
\hline
\end{tabular}

dalam menganalisis hubungan antara variabel laten dan diukur melalui variabel yang diamati. Evaluasi model dalam PLS memeriksa model pengukuran, berfokus pada signifikansi dan relevansi koefisien jalur dan penjelas model (Henseler \& Sarstedt, 2013)namely goodnessof-fit indices. In order to illustrate the behavior of the goodness-of-fit index (GoF).

Uji Persyaratan Instrumen Penelitian. Validitas merupakan ukuran yang menunjukan tingkat kevalidan suatu instrumen/kuisioner. Validitas instrumen diukur dengan menggunakan tekhnik analisis faktor (Umar 2005). Uji validitas digunakan untuk mengukur sah atau tidaknya penelitian. Uji validitas menggunakan korelasi pearson, keputusan mengetahui valid tidaknya butir instrumen. Jika pada tingkat signifikan $5 \%$ nilai $r$ hitung $>r$ variabel maka dapat dsimpulkan bahwa butir instrumen tersebut valid. (Supranto:2002).

Uji reliabilitas digunakan untuk menunjukkan sejauh mana alat pengukur yang digunakan dapat di percaya atau dilakukan untuk mengetahui konsistensi dan ketetapan pengukuran. Pengujian reliabilitas ditunjukkan oleh koefisien Alpha Croanbach. Coefficiant Alpha (Croanbach Alpha) yaitu koefisien reliabilitas yang menunjukkan seberapa baik item dalam suatu kumpulan secara positif berkorelasi satu sama lain. Jika hasil uji reliabilitas dengan Alpha Croanbach > 0,5 dikatakan reliabel.

Pengujian inner model biasa disebut juga dengan pengujian model struktural. Pengujian ini dinilai berdasarkan indeks Goodness of Fit (GoF). Indeks Gof dapat dihitung secara manual dengan rumus $\sum$. Tiga kategori Gof yaitu kecil 0,1 ; sedang $=0,25$; dan besar $=0,36$. Indeks GoF pada penelitian ini adalah 0,0459 sehingga dapat disimpulkan bahwa model penelitian ini baik (Tenenhaus, Amato, \& Vinzi, 2004). H1 : Bauran Pemasaran berpengaruh signifikan terhadap niat pembelian. H2 : Kualitas Pelayanan berpengaruh signifikan terhadap niat pembelian. H3: Niat berpengaruh signifikan terhadap pengambilan keputusan konsumen. H4 : Niat memediasi hubungan antara bauran pemasaran dan keputusan pembelian H5: Niat memediasi hubungan antara kualitas pelayanan dan keputusan pembelian. H6: Bauran pemasaran, dan kualitas pelayanan berpengaruh signifikan terhadap niat pembelian. H7: Bauran pemasaran, kualitas pelayanan, dan nat pembelian berpengaruh signifikan terhadap keputusan pembelian

\section{HASIL DANPEMBAHASAN}

Pada tabel 5 dijelaskan bagaimana variabel independent mempengaruhi dependen 
Tabel 3.

Validitas dan Reliabilitas Konstruk

\begin{tabular}{llll}
\hline \multicolumn{2}{c}{ Croanbach Alpa } & AVE \\
\hline Keputusan Pembelian & 0.753 & 0.668 \\
Kualitas Pelayanan & 0.908 & 0.548 \\
Bauran Pemasaran & 0.783 & 0.596 \\
Niat & 1.000 & 1.000 \\
\hline
\end{tabular}

Tabel 4.

Hasil Uji Model

\begin{tabular}{cccc}
\hline Variabel & AVE & R & \\
\hline Decision Purchasing & 0,668 & 0,448 & \\
Intention & 1 & 0,162 & \\
Marketing Mix & 0,596 & & \\
Service quality & 0,548 & & 0.214415 \\
Rata-rata & 0.703 & 0.305 & 0,0459 \\
\hline \multicolumn{4}{c}{ Ave x r } \\
Goodness of Fit
\end{tabular}

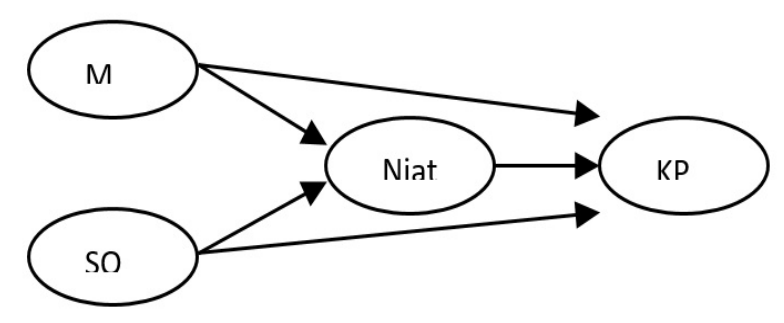

Gambar 1. Model penelitian

dan melalui variabel mediasi.

Uji hipotesis 1 dalam penelitian ini adalah variabel bauran pemasaran tidak berpengaruh signifikan terhadap niat pembelian karena nilai $\mathrm{p}$ value sebesar $0.8 \%$. Ketika pemasar menerapkan bauran pemasaran saja tanpa adanya variabel pendukung lainnya hasilnya akan negative terhadap niat pembelian konsumen. Tempat menjadi indikator tertinggi dalam pembentukan variabel bauran pemasaran. Walaupun secara keseleuruhan bauran pemasaran tidak dapat berpengaruh secara langsung terhadap keputusan pembelian, tetapi lokasi yang strategis, tempat pelayanan yang bersih dan tertata dengan baik membuat konsumen senang.

Uji hipotesis 2 dalam variabel kualitas pelayanan berpengaruh signifikan terhadap niat 
Tabel 5. Jalur Koefisien (SmartPls)

\begin{tabular}{lcc}
\hline & T Statistik (O-STDEV) & P Value \\
\hline Bauran Pemasaran ke niat (H1) & 0.210 & 0.834 \\
Kualitas Pelayanan ke niat (H2) & 2.505 & 0.013 \\
Niat ke keputusan pembelian (H3) & 4.533 & 0.000 \\
Bauran Pemasaran ke keputusan melalui niat (H4) & 0.491 & 0.624 \\
Kualitas pelayanan ke keputusan melalui niat (H5) & 2.105 & 0.036 \\
\hline
\end{tabular}

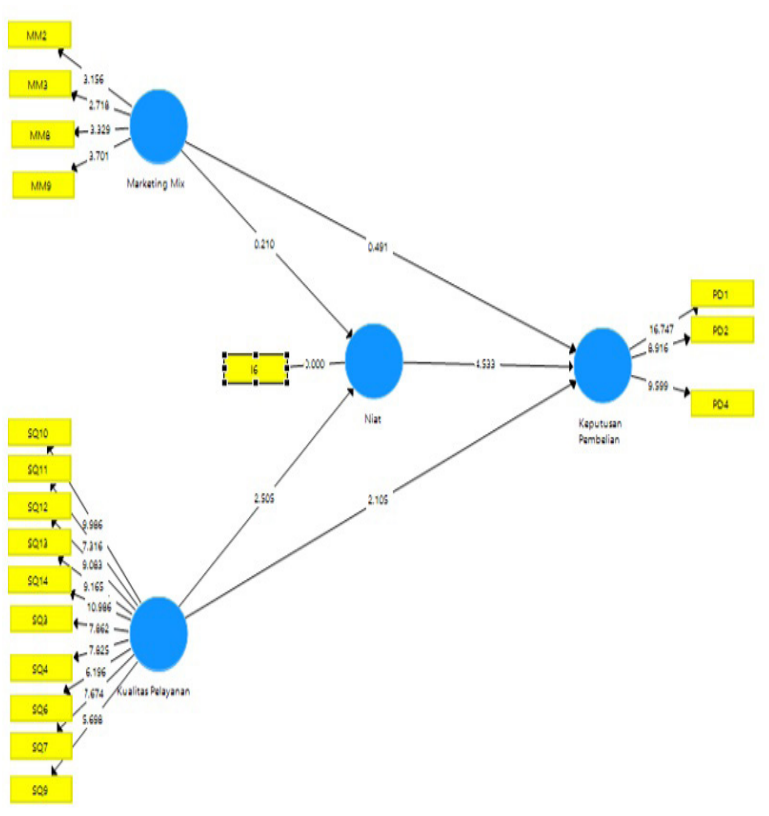

Gambar 2.

\section{Hasil oleh data PLS}

pembelian yang sesuai dengan hasil penelitian yang dilakukan, Hasil uji statistik yang dilakukan mendapatkan nilai $1.3 \%$ yang artinya uji hipotesis terdukung. Indikator empati yang mendapatkan skor tertinggi sebesar 0.827 yang artinya pelayanan karyawan dalam bersikap kepada konsumen dalam menciptakan hubungan emosional antar karyawan dan pelanggan. Pelayanan yang ramah dan peduli kepada pelanggan menjadikan nilai tersendiri bagi pelanggan dalam melihat suatu produk yang bernilai tinggi. Hasil penelitian ini mendukung hasil penelitian sebelumnya yang menjelaskan kualitas pelayanan berpengaruh penting dalam mempengaruhi perilaku konsumen dalam memilih. Faktor-faktor utama yang mempengaruhi perilaku konsumen adalah preferensi pelanggan dan kepuasan pelanggan (Tominc \& Pandit, 2012).

Uji Hipotesis 3 niat berpengaruh signifikan terhadap keputusan pembelian. persepsi konrol perilaku menjadi indikator pembentuk variabel niat dalam mempengaruhi keputusan pembelian. konsumen dengan sadar memilih produk dengan kemauan sendiri dan dengan segala risiko yang bisa terjadi. Strategi perusahaan yang dilakukan dalam variabel bauran pemasaran dan kualitas pelayanan mempengaruhi niat konsumen dalam membeli mobil. Semakin tinggi niat yang dibentuk dari strategi pemasaran tersebut berdampak pada jumlah pembelian yang dilakukan. Hasil penelitian ini juga didukung dari penelitian yang sudah dilakukan, bahwa niat mempengaruhi keputusan pembelian konsumen pada produk. Dalam menciptakan niat pelanggan pemasar harus berkonsentrasi pada atribut produk saat beriklan sehingga citra merek yang baik dapat diingat oleh konsumen sebelum membeli produk(Haque et al., 2015)

Uji Hipotesis 4 menjelaskan bahwa niat tidak dapat memediasi antara bauran pemasaran dengan keputusan pembelian. nilai didapatkan 0.820 lebih dari $5 \%$ ketentuan yang berlaku dalam memediasi. Sedangkan pada uji Hipotesis 5 menjelaskan bahwa niat memediasi antara kualitas pelayanan dengan keputusan pembelian secara signifikan.

Uji Hipotesis 6 menjelaskan bahwa bauran pemasaran, kualitas pelayanan secara 
Tabel 6.

R Square

\begin{tabular}{lll}
\hline & \multicolumn{1}{c}{ R Square } \\
\hline Niat Pembelian & 0.448 \\
Keputusan Pembelian & 0.162 \\
\hline
\end{tabular}

simultan (bersama-sama) mempengaruhi niat pembelian konsumen. Strategi yang dilakukan oleh perusahaan tidak bisa hanya berfokus pada satu variabel dalam mempengaruhi niat tetapi bagaimana dapat melakukan strategi pemasaran dengan sinergitas beberapa variabel dalam satu kesatuan yaitu dengan variabel kualitas pelayanan. Pengalaman konsumen setelah melihat apa yang dilakukan pemasar kepada konsumen akan berpengaruh terhadap niat pembelian konsumen. Penelitian sebelumnya juga menjelaskan bahwa tidak hanya meyakinkan pelanggan dengan fitur dan harga tetapi layanan serta pengalaman konsumen dapat mempengaruhi niat konsumen dalam berpikir untuk membeli sebuah produk (Khan \& Rahman, 2014).

Uji Hipotesis 7 menjelaskan bahwa bauran pemasaran, kualitas pelayanan dan niat secara simultan mempengaruhi keputusan pembelian konsumen.

Implikasi Penelitian

Berdasarkan penelitian yang telah dilakukan bahwa terdapat implikasi manajerial yang dapat digunakan sebagai langkah strategi perusahaan dalam pemasaran. Temuan menunjukan bahwa variabel strategi bauran pemasarantidakberpengaruhsignifikanterhadap niat beli konsumen jika hanya mengandalkan hanya satu strategi bauran pemasaran saja, perlu adanya tambahan variabel kualitas pelayanan agar hasilnya memperlihatkan positif terhadap niat pembelian dan pada akhirnya sampai pada keputusan pembelian karena perusahaan mobil tidak hanya menjual barang saja, tetapi juga menjual pelayanan sehingga kualitas pelayanan sangat berperan penting dalam kemajuan perusahaan. Kontribusi penelitian ini terhadap pengembangan ilmu pemasaran yaitu penggunaan indikator dalam bauran pemasaran diperlukan penambahan indikator lain yang dapat menyesuaikan dengan beberpaa kondisi penelitian seperti teori hubungan kedekatan emosional dalam mempengaruhi keputusan pembelian serta penekanan pada internal pemasaran dalam perusahaan. Internal pemasaran mempunyai implikasi penting dalam pemenuhan kebutuhan karyawan yang harus dipenuhi oleh perusahaan karena ketika karyawan puas dengan hal tersebut, maka karyawan akan memuaskan pelanggan eksternal (Akroush, Abu ElSamen, Samawi, \& Odetallah, 2013).

Keterbatasan dan saran untuk penelitian di masa depan

Keterbatasan penelitian ini dengan karaketristik responden yang belum terlalu spesifik. Misalnya apakah sudah pernah membeli mobil atau pembelian ulang sehingga daftar kuesioner dan perlakuannya berbeda serta jumlah populasi responden yang lebih mewakili tiap kabupaten di Provinsi Lampung. Penambahan variabel penelitian juga harus dilakukan agar lebih dapat diketahui faktorfaktor yang dapat mempengaruhi niat beli konsumen seperti pengaruh budaya dan tekhnologi yang semakin berkembang, perusahaan harus lebih cepat dan tanggap terhadap perubahan tersebut sehingga dapat selaras dengan strategi yang digunakan. 


\section{SIMPULAN}

Bauran pemasaran tidak dapat berdiri sendiri dalam membangun pengaruh terhadap keputusan pembelian, diperlukan adanya kolaborasi yang bersinergis dalam mendapatkan hasil yang sempurna, seperti dengan variabel kualitas pelayanan yang baik. Kualitas pelayanan yang semakin baik mempengaruhi niat konsumen dalam membeli mobil. Internal marketing dalam perusahaan harus ditingkatkandalam memberikan pelayanan yang baik. Pelayanan yang baik akan berdampak positif pada niat pembelian dan hasil penelitian membuktikan bahwa semakin tinggi niat konsumen untuk membeli akan berdampak pada keputusan pembelian. Pelatihan kepada karyawan dan peningkatan pengetahuan karyawan terhadap produk menjadikan langkah yang tepat dalam membangun strategi yang tepat dalam meningkatkan penjualan.

\section{REFERENSI}

Akroush, M. N., Abu ElSamen, A. A., Samawi, G. A., \& Odetallah, A. L. (2013). Internal marketing and service quality in restaurants. Marketing Intelligence \& Planning, 31(4), 304-336. https://doi. org/10.1108/02634501311324834

D’Souza, C., Marjoribanks, T., Young, S., Sullivan Mort, G., Nanere, M., \& John, J. J. (2019). Environmental management systems: an alternative marketing strategy for sustainability. Journal of Strategic Marketing, 27(5), 417-434. https://doi.org/10.108 0/0965254X.2018.1430054

Gordon, R. (2012). Re-thinking and re-tooling the social marketing mix. Australasian Marketing Journal, 20(2), 122-126. https:// doi.org/10.1016/j.ausmj.2011.10.005

Haque, A., Anwar, N., Yasmin, F., Sarwar, A., Ibrahim, Z., \& Momen, A. (2015). Purchase Intention of Foreign Products. $S A G E$ Open, 5(2), 215824401559268. https://doi. org/10.1177/2158244015592680

Henseler, J., \& Sarstedt, M. (2013). Goodness- of-fit indices for partial least squares path modeling. Computational Statistics, 28(2), 565-580. https://doi.org/10.1007/s00180012-0317-1

Hooper, D., Coughlan, J., \& Mullen, M. R. (2013). The servicescape as an antecedent to service quality and behavioral intentions. Journal of Services Marketing, 27(4), 271-280. https://doi. org/10.1108/08876041311330753

Išoraite, M. (2016). P) IF: 4.321 (CosmosImpactFactor), 2.532 (I2OR) Cite This Article: Margarita Išoraitè. International Journal of Research-Granthaalayah, 4(6), 25-37. https://doi.org/10.5281/zenodo. 56533

Khan, I., \& Rahman, Z. (2014). Influence of Experiential Marketing on Customer Purchase Intention: A Study of Passenger Car Market. Management and Labour Studies, 39(3), 319-328. https://doi. org/10.1177/0258042x15572411

Kitapci, O., Akdogan, C., \& Dortyol, İ. T. (2014). The Impact of Service Quality Dimensions on Patient Satisfaction, Repurchase Intentions and Word-of-Mouth Communication in the Public Healthcare Industry. Procedia - Social and Behavioral Sciences, 148, 161-169. https://doi. org/10.1016/j.sbspro.2014.07.030

Lim, Y. J., Osman, A., Salahuddin, S. N., Romle, A. R., \& Abdullah, S. (2016). Factors Influencing Online Shopping Behavior: The Mediating Role of Purchase Intention. Procedia Economics and Finance, 35(October 2015), 401-410. https://doi. org/10.1016/s2212-5671(16)00050-2

Singh, M. (2012). Marketing Mix of 4P'S for Competitive Advantage. IOSR Journal of Business and Management, 3(6), 40-45. https://doi.org/10.9790/487x-0364045

Tominc, dr. P., \& Pandit, R. (2012). Study of The Impact of Service Quality on Consumer Behavior in Internet Banking Services. Paripex - Indian Journal 
Of Research, 3(1), 131-133. https://doi. org/10.15373/22501991/jan2014/40

Yadav, R., \& Pathak, G. S. (2016). Young consumers' intention towards buying green products in a developing nation: Extending the theory of planned behavior. Journal of Cleaner Production, 135, 732-739. https:// doi.org/10.1016/j.jclepro.2016.06.120 